NASA Technical Memorandum 103118

\title{
Progression of Damage and Fracture in Composites Under Dynamic Loading
}

Levon Minnetyan

Clarkson University

Potsdam, New York

Pappu L.N. Murthy and Christos C. Chamis

Lewis Research Center

Cleveland, Ohio

Prepared for the

31 st Structures, Structural Dynamics and Materials Conference cosponsored by the AIAA, ASME, ASCE, AHS, and ASC Long Beach, California, April 2-4, 1990

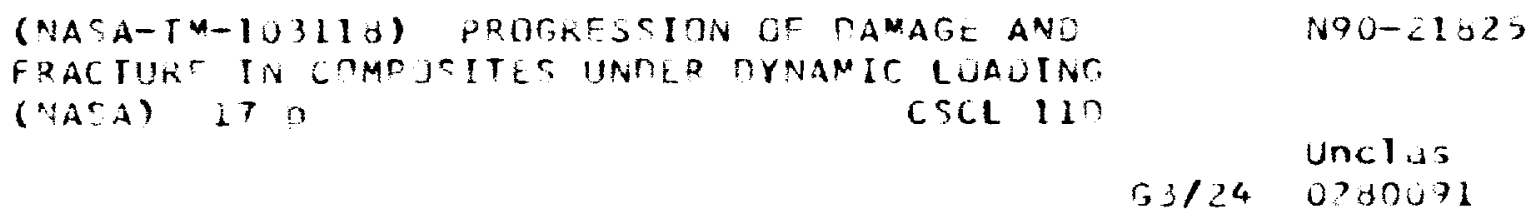


. 


\title{
PROGRESSION OF DAMAGE AND FRACTURE IN COMPOSITES UNDER DYNAMIC LOADING
}

\author{
Levon Minnetyan* \\ Clarkson University \\ Department of Civil and Environmental Engineering \\ Potsdam, New York 13676
}

Pappu L.N. Murthy and Christos C. Chamis

National Aeronautics and Space Administration

Lew is Research Center

Cleveland, Ohio 44135

\section{SUMMARY}

A new computational simulation method is presented to evaluate the dynamic aspects of composite structural response and durability that have not been simulated previously. Composite structural behavior under any loading condition, geometry, composite system, laminate configuration, and boundary conditions can now be simulated. Structural degradation, delamination, fracture, and damage propagation are included in the simulation. An angle-plied composite plate structure under normal impact loading is used as an example to demonstrate the versatility of the simulation method.

\section{INTRODUCT ION}

The behavior of $\mathrm{f}$ iber composite laminates during progressive damage and fracture has become of increasing interest in recent years due to the multitude of benefits that composites offer in practical engineering applications such as lightweight airframes, engine structures, space structures, marine and other transportation structures, high-precision machinery, and structural members in robotic manipulators. Composite structures lend themselves to tailoring to achieve desirable characteristics such as a high strength to weight ratio, dimensional stability under extreme thermal and hygral fluctuations, and the capability to allow controlled detectability such as in the Stealth technology. Because of the infinite possibilities with material combinations, composite geometry, ply orientations, and loading conditions, it is essential to have a reliable computational capability to predict the behavior of composites under any loading condition, geometry, composite material combinations, and boundary conditions. The predictions of damage initiation, progressive damage, and progressive fracture are important in evaluating the safety and reliability of composite structures.

The behavior of composites during progressive fracture has been investigated both experimentally and by computational simulation (refs. 1 and 2). The concept and computational foundations of CODSTRAN (COmposite Durability STRuctural ANalysis) were first laid out by Chamis and Smith in 1978 (ref. 1). The computational simulation of progressive fracture predicted by CODSTRAN was found to be in reasonable agreement with experimental data from coupon tension tests conducted at NASA Lewis Research Center (ref. 2). From the very beginning, CODSTRAN was designed to be a modular and open ended computer code. The modular nature of CODSTRAN has enabled the upgrading of nearly the entire code as new and improved modules have become available for composite mechanics,

\footnotetext{
${ }^{\star}$ Summer Faculty Fellow at Lewis Research Center.
} 
structural analysis, and failure criteria. Due to the open-endedness of CODSTRAN, recent additions to the code have enabled monitoring the variations in structural properties such as natural frequencies, vibration mode shapes, and buckling modes during progressive fracture (ref. 3). In these past studies computational simulation of progressive fracture and failure has been primarily concentrated on the effects of monotonically increasing static loading on the progression of damage and fracture. The objective of the current research is to develop and demonstrate the computer simulation of composite behavior with damage progression and fracture under dynamic loading applied normal to the laminate, including loading rates that are sufficiently abrupt to be considered impulsive.

For the purpose of this discussion, composite structural damage under dynamic loading may be classified into three levels: (1) Initial Damage, (2) Damage Growth, and (3) Fracture Progression. (1) Initial Damage refers to the initiation of structural deterioration. It is usually localized under the applied normal dynamic loading and may involve one or more plies of the laminate. This is generally a matrix dominated failure (matrix microcracking caused by transverse as well as shear stresses within the damaged plies). (2) increased loading. There may be additional failure modes and/or additional plies participating in the damage at this secondary level. (3) Fracture Progression refers to the growth of damage and fracture from a localized area under the impact loading to other parts of the composite structure.

\section{BACKGROUND}

CODSTRAN (COmposite Durability STRuctural ANalyzer) is a computer code developed for the analysis of composite structures; keeping track of progressive damage resulting from the application of loads (refs. 1 and 3 ). It consists of an executive module, an analys is package for micromechanics and macromechanics (ICAN), and a finite element analysis module (MHOST). The ICAN (Integrated Composites ANalyzer) (refs. 4 and 5) and MHOST (ref.6) computer codes are originally independent codes that have been integrated into CODSTRAN as analysis modules.

The ICAN computer code incorporates the cumulative result of composites research at NASA Lewis Research Center on polymer matrix multilayer angle-plied composites. ICAN is capable of determining the ability of the composite laminate to endure stresses and deformations caused by applied loading and environmental effects such as temperature and humidity. ICAN predicts all possible internal damage and fracture in the composite laminate. Fourteen distinct failure modes are checked by ICAN at each load increment during a CODSTRAN analysis stage. These failure modes include the failure criteria associated with the positive and negative limits of the six stress components, a modified distortion energy failure criterion, and delamination due to relative rotation. Another important capability of ICAN is to compute the anisotropic elastic constants from the physical information on the composite laminate. ICAN utilizes a resident data bank that contains the properties of typical fiber and matrix constituent materials, with provisions to add new constituents as they become available. The piecewise linear constitutive relationships determined by ICAN are supplied to the MHOST finite element analysis module for the definition of nodal finite element properties at each load increment. The executive module 
of CODSTRAN determines the appropriate step size for each load increment and directs the computational simulation of nonlinear-inelastic, large deformation progressive damage and fracture behavior under loading.

The integration of ICAN with a general purpose structural analys is code results in a piecewise linear incremental loading analyzer with equilibrium checks at each local iteration for each load increment. The current version of CODSTRAN uses MHOST as the structural analysis module due to the ability of the MHOST quadrilateral shell element to accept the composite laminate forcedeformation relations predicted by ICAN.

As an example of the capabilities of the CODSTRAN code existing prior to the current research, the load-displacement relationship computed by CODSTRAN for a typical composite plate structure is presented in figure 1 . This structure is loaded by a uniform static tensile loading applied in the longitudinal direction in the plane of the composite. The apparent softening of the simulated load-displacement relationship with increased loading is because of the initiation and progression of damage and fracture in the composite plate. After the application of the last load increment the plate is torn into two pieces.

The CODSTRAN incremental loading procedure uses an accuracy criterion based on the allowable maximum number of damaged nodes during the application of a load increment. If too many nodes are damaged or fractured during a load increment, incremental loads are reduced and the analys is is repeated. 0therwise, if there is an acceptable amount of incremental damage, the load increment is kept constant but the constitutive properties and the structural geometry are updated to account for the damage and deformations in the previous increment. The structure is then reanalyzed for further damage and deformation. If, after an incremental analysis step, there is no damage as determined by ICAN, the structure is considered to be in equilibrium and an additional load increment is applied. Analysis is stopped when global structural fracture is imminent.

During the computational simulation of progressive fracture, CODSTRAN also keeps track of degradation of structural integrity such as natural frequencies, vibration modes, buckling loads and buckling modes of the structure. CODSTRAN has been experimentally verified for the simulation of progressive fracture and failure under monotonically increasing static loading applied in the plane of the composite (refs, 1 and 2).

In the present paper, CODSTRAN is augmented to conduct the simulation of progressive fracture under dynamic loading applied normal to the laminate. Loading rates for the newly augmented CODSTRAN code may vary from relatively slow loads that could be simulated by a pseudo-static analysis, to much higher loading rates that may be classified as impulsive. All dynamic effects are taken into account within the limitations of the thick shell finite element model. Effects that are not yet included are dynamic wave propagation across the thickness of the composite laminate and strain rate effects in the constitutive relationships. The dynamic version of CODSTRAN uses a similar incremental loading procedure as in the static version. However, inertial effects are also taken into account. The dynamic time history is simulated by using the Newmark implicit integration algorithm that is available in the MHOST module. It is necessary to maintain the incremental loading process while updating the nodal coordinates, velocities, accelerations, and constitutive relations in the 
dynamic analysis procedure in order to closely simulate the realistic progression of damage and fracture. In the augmented CODSTRAN program the effective loads at each dynamic load increment are expressed in terms of the incremental loads and the structural mass, nodal accelerations, velocities, and di splacements.

The dynamic loading may be specified as any arbitrary function of time. The time domain is subdivided into a sufficient number of time intervals for accurate dynamic analysis. High frequency vibration modes are usually significant during dynamic impact loading, requiring a relatively small time step size. However, structural geometry and laminate properties do not change significantly at each time step. The number of time steps to cause considerable change in structural geometry and/or to cause possible laminate damage constitute the dynamic load increment. The load increment size is dictated by the criterion on the allowable number of nodes of the structure with incremental damage. The duration of a load increment usually takes many time increments. Laminate properties and structural geometry are updated at the end of each load increment as computed. Within a load increment the equations of motion are solved to obtain the time history response using the number of time increments contained in that load increment. Time histories for consecutive load increments are chained together with the appropriate continuity conditions to obtain the overall time history response. The temporal discretization requirements depend on the rate of the dynamic loading application as well as on the structural properties. The spatial discretization needs are mainly dependent upon the required extent and accuracy of damage and progressive fracture analysis after the initiation of damage and large structural deformations.

\section{EXAMPLE COMPOSITE STRUCTURE AND ANALYSIS}

As an example of the augmented simulation capabilities in CODSTRAN, an intermediate stiffness T-300/Epoxy (Thornel-300 graphite fibers in an epoxy matrix) composite structure is selected for analys is of dynamic response under impulsive loading. A composite square plate (3- by 3 -in.), supported along its four edges is loaded by a concentrated normal dynamic load at the center (fig. 2). Large deformations are included in the computational simulation. The finite element model consists of 64 plate elements as shown in figure 3 . The finite element model is deliberately chosen to be somewhat coarse to ensure a reasonable computer turnaround time for this demonstration example. The laminate conf iguration is $+45 /-45 /-45 /+45 /$, with a total composite plate thickness of $0.02 \mathrm{in}$. All edges have been restrained against displacement in the $z$ direction in all cases. Within this constraint, two types of support conditions are considered. In the first type, support nodes are allowed to move in the $x-y$ plane (the plane of the undeformed composite plate). In the second type of support, boundary nodes are restrained against displacement in all directions. The first and second types of support conditions will be referenced to as released and restrained supports, respectively.

The concentrated transient load is assumed to increase linearly with time, as shown in figure 4, until global fracture of the composite plate structure. Three loading rates are considered. These loading rates are $0.1,2.0$, and $3.5 \mathrm{lb} / \mu \mathrm{sec}$. Figure 5 shows the dynamic load-deflection histories at these three rates for the first type (released) boundary support condition. The displacements are very small for the first load increment because of the large 
inertial load imparted when the structure is initially set in motion. Also, the higher the loading rate, the smaller the displacement because of the higher inertial force. After the first load increment, there is a dramatic increase in displacement, especially for the $0.1 \mathrm{lb} / \mu \mathrm{sec}$ loading rate. In this case, the time is sufficiently long for the entire plate to be set in motion. After a center deflection of approximately 0.3 in. membrane forces become significant and the incremental deflections are reduced. It may be noted that even though the support nodes are free to move in the $x-y$ plane, membrane effects are developed due to the restraint of boundary nodes in the $z$ direction and the square geometry of the plate. If the support nodes were not restrained in the $z$ direction, the corners of the plate would lift up and fold along the diagonals to allow for a truly unrestrained deflection of the plate without membrane forces. The load corresponding to $0.3 \mathrm{in}$. center deflection is $60 \mathrm{lb}$. This loading level also causes initial local damage in the composite laminate (ply 1 - the first ply on the tension side of the plate). The initial damage is caused by the ply transverse tensile stresses reaching their limits.

Figure 6 shows the contours of ply 1 transverse stresses that cause the damage. Figure 7 shows the much lower intensities of the same stresses after CODSTRAN accounts for the damage, redefines the material properties, and reaches a dynamic equilibrium with the redefined properties. Numerical results show that the transverse ply stress is zero at the damaged center node. However, this zero ply stress does not appear as a contour in figure 7 because the damage is highly localized involving only the center node under the load. Figure 8 shows the deformed finite element mesh with displacement contours immediately after initial damage. The deformed structure continues to carry additional load, sustaining approximately constant incremental displacements with each load increment. Other plies participate in the laminate damage growth at approximately $240 \mathrm{lb}$ loading. The maximum deflection at the center node under $240 \mathrm{lb}$ loading is $0.7 \mathrm{in}$. It may be noted from figure 5 that there is no apparent change in the overall stiffness due to localized transverse damage in the plies of the laminate. This lack of sensitivity to damage is because membrane forces are much more significant compared to flexural forces under large deformations. Localized damage in the ply transverse directions reduces only the flexural stiffness of the laminate. The entire structure participates in the dynamic response similar to a static loading. The deformed finite element mesh with displacement contours corresponding to $240 \mathrm{lb}$ loading at $0.1 \mathrm{lb} / \mu \mathrm{sec}$ is shown in figure 9 .

For the $2.0 \mathrm{lb} / \mu \mathrm{sec}$ loading case, damage is initiated by the same transverse stress limit criterion in the tension plies. However, initial damage occurs at a higher dynamic load of $75 \mathrm{lb}$. The center node displacement corresponding to the $75 \mathrm{lb}$ damage initiation load is approximately $0.07 \mathrm{in}$., as it may be observed from figure 5 . For the $3.5 \mathrm{lb} / \mu \mathrm{sec}$ loading rate initial damage occurs at a load of $105 \mathrm{lb}$. The maximum def lection corresponding to $105 \mathrm{lb}$ for this case is also approximately $0.07 \mathrm{in}$. The 2.0 and $3.5 \mathrm{lb} / \mu \mathrm{sec}$ loading rates both cause the same type of response that is characterized by significant local deformations that do not engage the entire plate.

Figure 10 shows the deformed finite element mesh and the displacement contours corresponding to the initial damage load of $105 \mathrm{lb}$ applied at the rate of $3.5 \mathrm{lb} / \mu \mathrm{sec}$. The initial damage mode is the transverse stress limit as in the slower loading cases. However, in this case three plies are failed simultaneously. Figures 11 and 12 show the ply 1 transverse stresses, before and after 
dynamic equilibrium, respectively, at the time of initial damage. Further loading after initial damage does not significantly change the displacement pattern. However, the local deformations under the load are further increased and longitudinal stress failure occurs in ply 1 at $122.5 \mathrm{lb}$. The ply 1 longitudinal (fiber direction) stresses are shown in figures 13 and 14 , before and after dynamic equilibrium is reached by CODSTRAN. In figure 13, ply 1 longitudinal stresses at the center node are seen to reach their limit. In figure 14 ply 1 has failed under the load and the corresponding longitudinal ply stress at the center of the plate is zero. The corresponding finite element mesh and displacement contours are shown in figure 15. For this example. ply failures that are initiated by the tensile stress limits usually activate the modified distortion energy failure criterion simultaneously.

Next, the same loading at the same rates is applied to the composite plate with the second type support where all boundary nodes are restrained from translation in all directions. Figure 16 shows the load-deflection relations for the three loading rates applied to the plate with the restrained supports. For the $0.1 \mathrm{lb} / \mu \mathrm{sec}$ loading rate, membrane action becomes much more important compared to the case of released supports and the displacements are significantly reduced as the restrained boundaries do not allow the majority of the plate to participate in transverse motion. Soon after the initial setting of the plate in motion, inertial forces become negligible because the loading rate is relatively slow. CODSTRAN analys is shows a 0.07 in. center deflection at the end of the first load increment, under $30 \mathrm{lb}$ load. During the next load increment, damage is initiated at the center node in ply 1 by reaching the stress limit in the transverse tensile stress. The 60 lb load that initiates damage is the same as what was required to initiate damage under the released type support condition. However, the displacement under the load is only twothirds of the displacement under the released support case. Figure 17 shows the transverse stresses that cause damage at the center node in ply 1 . Figure 18 shows the same stresses at much reduced levels immediately after damage when dynamic equilibrium is reached with the new structural properties that take the damage into account. Figure 18 indicates zero transverse stress in ply 1 at the center node where the damage occurred. Figure 19 shows the deformed finite element model with values of the displacements after the initial damage. Damage growth continues gradually as the transverse stress limits are exceeded in the other plies. Ply 2 fails at $180 \mathrm{lb}$, ply 3 fails at $210 \mathrm{lb}$, and ply 4 fails at $240 \mathrm{lb}$. All ply failures at this stage are in the transverse directions. Figure 20 shows the deformed plate with displacement contours after all plies are damaged in their transverse directions.

The restrained boundary conditions affect the structural response at higher loading rates as well. With the restrained supports, initial damage occurs at lower magnitudes of the applied load since stresses are built up more quickly. However, the qualitative effect of the loading rate is similar in that the higher the rate of loading, the larger is the applied load to initiate
damage.

Figure 21 shows the deformed finite element model immediately after the initiation of damage, under $87.5 \mathrm{lb}$ at $3.5 \mathrm{lb} / \mu \mathrm{sec}$. Figure 21 is comparable to figure 10 which shows the deformed structure at the time of initial damage by the same load under the released support conditions. Failure modes are also comparable as the first, second, and third plies fail simultaneously in their 
transverse directions. However, there are some differences. First, the initiation of damage under the restrained boundary conditions starts at a lower load. Second, the damage region is spread over a much larger area of the laminate under the restrained boundaries. Figure 22 shows the transverse stress contours in ply 1 immediately before equilibrium iteration by CODSTRAN at the time of damage initiation. Approximately one third of the entire plate is participating in damage. Whereas in the case of the released supports, for which initial failure stresses are depicted in figure 11, initial damage was limited to the center node. For the restrained support condition, figure 23 shows much lower transverse stresses in ply 1 after CODSTRAN has progressed fracture until the structure reaches dynamic equilibrium.

Additional loading after initial damage causes the fourth ply to fail in the transverse direction and the first ply to fail in the longitudinal direction at $105 \mathrm{lb}$.

Table I summarizes the initial damage and damage growth modes for all six loading cases considered.

\section{CONCLUSIONS}

An example structure is used to demonstrate the simulation of composite behavior under different loading rates, with two different boundary support conditions. At a relatively slow loading rate the dynamic response behavior is similar to that of a static loading; as the failure mode under slow dynamic loading has all characteristics of the failure that would also occur under a statically applied loading. This static failure mode is characterized by large deflections involving most of the structure. When the loading rate is sufficiently high, inertial forces and local effects become significant and the failure mode changes to a dynamic failure mode. In the dynamic failure mode inertial forces are significant, structural deflections are small, and large deformations are localized to the impact zone. At high loading rates, overall structural deformations at the time of damage initiation do not appear to be affected by the support conditions at the boundaries. However, stresses and damage propagation are influenced significantly by the boundary conditions. If the supports are restrained, damaged zones are much more widespread. On the other hand if supports are not restrained damage zones are localized to a small region under the applied load.

With the presented research, a new dynamic computational capability has been implemented in CODSTRAN. The code is now capable of simulating the behavior of composites under any loading, geometry, material combinations, fiber orientations, tailoring, and boundary conditions. Structural degradation, delamination, fracture, and damage propagation are included in the simulation. The computational model is continually updated during the simulation of composite response, using the degraded properties as local failures occur. Under impact loading, CODSTRAN can be used for the prediction of the type of failure as either localized impact penetration or more distributed flexural failure. CODSTRAN is also capable of monitoring degradation of structural properties such as natural frequencies, vibration mode shapes, and buckling loads during progressive fracture (ref, 3). Current research is aimed to verify and further develop the computational simulation by the addition of a new module for computing the global fracture toughness of composite laminates. Objectives for 
continuing research include combining structural shell elements with solid elements for more refined representation of the loading zone, computation of the impact loading by including the impacting object in the solution, representation of strain rate effects in the constitutive relationships, fluid composite structure interaction, dynamic impact loading and hydrodynamic shock loading of submerged composites, composite degradation under cyclic loading, and nondestructive evaluation of remaining service life in composites.

\section{REFERENCES}

1. Chamis, C.C. and Smith, G.T., "Composite Durability Structural Analysis," NASA TM-79070, Nov. 1978.

2. Irvine, T.B. and Ginty, C.A., "Progressive Fracture of Fiber Composites," NASA TM-83701, Oct, 1983.

3. Minnetyan, L., Murthy, P.L.N. and Chamis, C.C., "Structural Behavior of Composites with Progressive Fracture," AIAA 89-1271, Apr. 1989.

4. Murthy, P.L.N. and Chamis, C.C., "ICAN: Integrated Composites Analyzer," J. Composite Technology Research, v. 8, Spring 1986, p. 8-17.

5. Murthy, P.L.N. and Chamis, C.C., "Integrated Composite Analyzer (ICAN): Users and Programmers Manual," NASA TP-2515, Mar. 1986.

6. Nakazawa, S., Dias, J.B. and Spiegel, M.S., "The MHOST Finite Element Program: 3-D Inelastic Analys is Methods for Hot Section Components:

Volume II - User's Manual," NASA CR-182235, July 1989. 
TABLE I. - SLMMARY OF FAILURE MODES FOR PRESENTED RESULTS

\begin{tabular}{|c|c|c|c|c|c|c|}
\hline Support & \multicolumn{3}{|c|}{ Released } & \multicolumn{3}{|c|}{ Restrained } \\
\hline $\begin{array}{l}\text { Loading } \\
\text { rate, } \\
\text { lb/ } / \text { sec }\end{array}$ & 0.1 & 2.0 & 3.5 & 0.1 & 2.0 & 3.5 \\
\hline $\begin{array}{l}\text { Load at } \\
\text { initial } \\
\text { damage, } \\
\text { lb }\end{array}$ & 60 & 75 & 105 & 60 & 60 & 87.5 \\
\hline $\begin{array}{l}\text { Initial } \\
\text { damage } \\
\text { modes }\end{array}$ & $\begin{array}{r}\sigma_{222} T \text {, ply } 1 \\
\text { MDE, ply } 1\end{array}$ & $\sigma_{\ell 22} \mathrm{~T}$, plies 1,2 & $\begin{array}{l}\sigma_{\ell 22} \mathrm{~T}, \text { plies } 1,2,3 \\
\text { MDE, plies } 1,2\end{array}$ & $\sigma_{\ell 22} T$, ply 1 & $\begin{array}{r}\sigma_{\ell 22} \mathrm{~T}, \text { plies } 1,2 \\
\mathrm{MDE}, \text { ply } 1\end{array}$ & $\sigma_{\ell 22} T$, plies $1,2,3$ \\
\hline $\begin{array}{l}\text { Load at } \\
\text { damage } \\
\text { growth, } \\
\text { Ib }\end{array}$ & 240 & 90 & 122.5 & 180 & 75 & 105 \\
\hline $\begin{array}{l}\text { Damage } \\
\text { growth } \\
\text { modes }\end{array}$ & $\begin{array}{r}\sigma_{\ell 22} \mathrm{~T}, \text { plies } 2,3 \\
\text { RR, ply } 2\end{array}$ & $\sigma_{\ell 22} \mathrm{~T}$, ply 3 & $\begin{array}{lll}\sigma_{\ell 22} \mathrm{~T}, & \text { ply } & 4 \\
\sigma_{\ell 11} \mathrm{~T} & \text { ply } & 1\end{array}$ & $\sigma_{\ell 22} \mathrm{~T}$, ply 2 & $\sigma_{\ell 22} T$, ply 3 & $\begin{array}{lll}\sigma_{\ell 22} \mathrm{~T}, & \text { ply } & 4 \\
\sigma_{\ell 11} \mathrm{~T}, & \text { ply } & 1\end{array}$ \\
\hline
\end{tabular}

Notation: $\sigma_{222} \mathrm{~T}$ - Tensile failure at transverse stress limit for ply.

$\sigma 011^{\mathrm{T}}$ - Tensile failure at longitudinal stress limit for ply.

$M D E$ - Failure according to modified distortion energy criterion.

RR - Failure according to relative rotation limit.

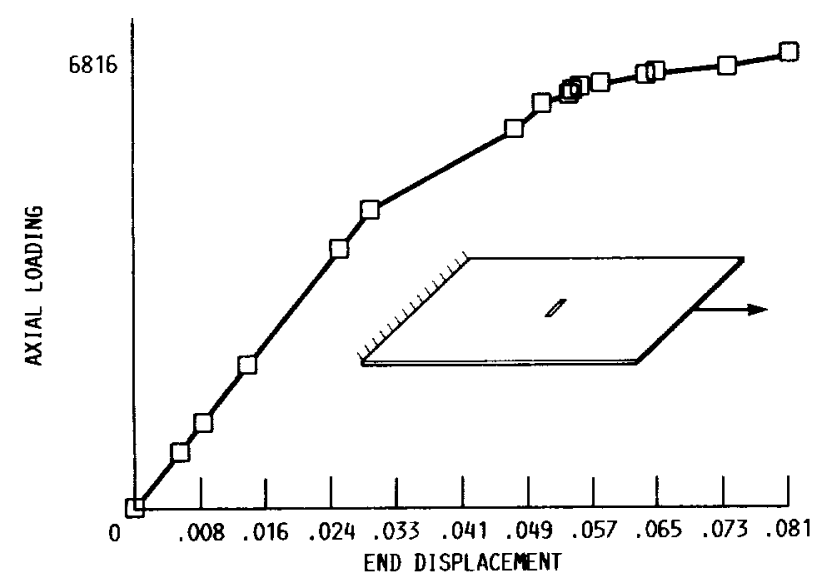

FIGURE 1. - LOAD-DISPLACEMENT RELATIONSHIP UNDER STAIIC AXIAL LOADING.

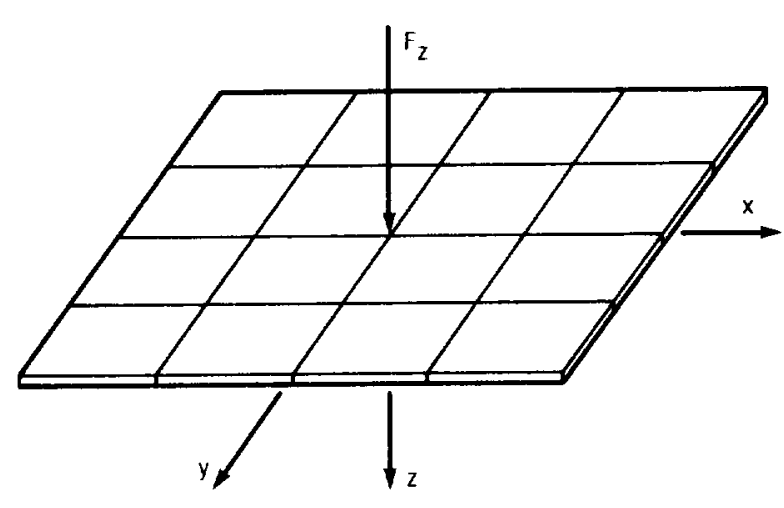

FiguRE 2. - RECTANGULAR PLATE MODEL WITH NORMAL LOAD. 


\begin{tabular}{|c|c|c|c|c|c|c|c|}
\hline $\begin{array}{r}73 \\
57\end{array}$ & $\begin{array}{r}4 \\
58 \\
\end{array}$ & $\begin{array}{l}75 \\
59\end{array}$ & $\begin{array}{r}76 \\
60 \\
\end{array}$ & \begin{tabular}{|r|}
77 \\
61 \\
\end{tabular} & $\begin{array}{l}78 \\
62\end{array}$ & $\begin{array}{r}79 \\
63\end{array}$ & \begin{tabular}{|l|}
80 \\
64
\end{tabular} \\
\hline $\begin{array}{l}64 \\
49\end{array}$ & \begin{tabular}{|l|}
65 \\
50
\end{tabular} & $\begin{array}{r}66 \\
51\end{array}$ & $\begin{array}{r}67 \\
52\end{array}$ & \begin{tabular}{|r|}
68 \\
53
\end{tabular} & $\begin{array}{r}69 \\
54\end{array}$ & $\begin{array}{r}70 \\
55\end{array}$ & $\begin{array}{r}71 \\
56\end{array}$ \\
\hline 55 & $\begin{array}{l}56 \\
42\end{array}$ & ${ }^{57} 43$ & $\begin{array}{l}58 \\
44\end{array}$ & \begin{tabular}{|l}
59 \\
45
\end{tabular} & $\begin{array}{l}60 \\
46\end{array}$ & ${ }^{61}$ & \begin{tabular}{|l|}
62 \\
48
\end{tabular} \\
\hline $\begin{array}{l}46 \\
33\end{array}$ & $\begin{array}{r}47 \\
34\end{array}$ & $\begin{array}{l}48 \\
35\end{array}$ & $\begin{array}{r}49 \\
36\end{array}$ & \begin{tabular}{|l|}
50 \\
37
\end{tabular} & $\begin{array}{l}51 \\
38\end{array}$ & \begin{tabular}{|r|}
52 \\
39
\end{tabular} & $\begin{array}{l}53 \\
40\end{array}$ \\
\hline $\begin{array}{r}37 \\
25 \\
\end{array}$ & $\begin{array}{l}38 \\
26\end{array}$ & \begin{tabular}{|l|}
39 \\
27 \\
\end{tabular} & $\begin{array}{r}40 \\
28\end{array}$ & \begin{tabular}{|l|}
41 \\
29
\end{tabular} & $\begin{array}{l}42 \\
30\end{array}$ & $\begin{array}{r}43 \\
31\end{array}$ & \begin{tabular}{|l}
44 \\
32
\end{tabular} \\
\hline $\begin{array}{r}28 \\
4^{17} \\
\end{array}$ & ${ }^{29}{ }_{18}$ & $\begin{array}{l}30 \\
19\end{array}$ & ${ }_{20}^{31}$ & 32 & ${ }^{33}{ }_{22}$ & ${ }_{23}^{34}$ & ${ }_{24}^{35}$ \\
\hline $\begin{array}{c}19 \\
9\end{array}$ & $\begin{array}{l}20 \\
\times \quad 10 \\
\end{array}$ & 21 & \begin{tabular}{|l|}
22 \\
12
\end{tabular} & $\begin{array}{r}23 \\
13\end{array}$ & $\begin{array}{l}24 \\
14\end{array}$ & $\begin{array}{r}25 \\
15\end{array}$ & \begin{tabular}{|l|}
26 \\
16
\end{tabular} \\
\hline $\begin{array}{r}10^{2} \\
1\end{array}$ & ${ }^{11} \begin{array}{l}11 \\
\end{array}$ & ${ }^{12} 3$ & 13 . & $\begin{array}{ll}14 & \\
& 5\end{array}$ & $\begin{array}{ll}15 & \\
& 6\end{array}$ & $\begin{array}{ll}16 & \\
& 7\end{array}$ & 178 \\
\hline & & & & & & & \\
\hline
\end{tabular}

FigURE 3. - FINITE ELEMENT MODEL.

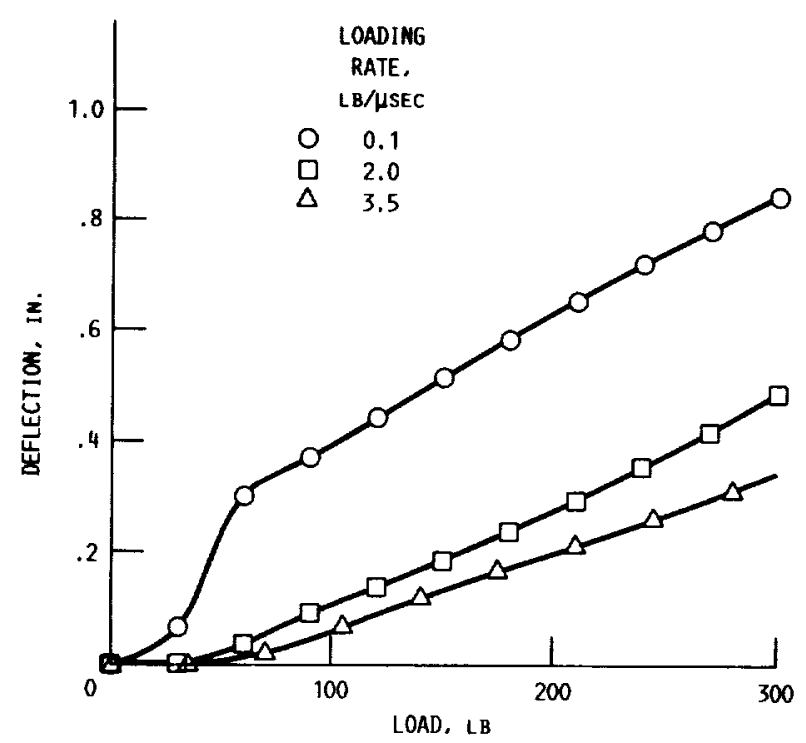

FIGURE 5. - LOAD-DEFLECTION RELATIONSHIPS FOR RELEASED SUPPORTS.

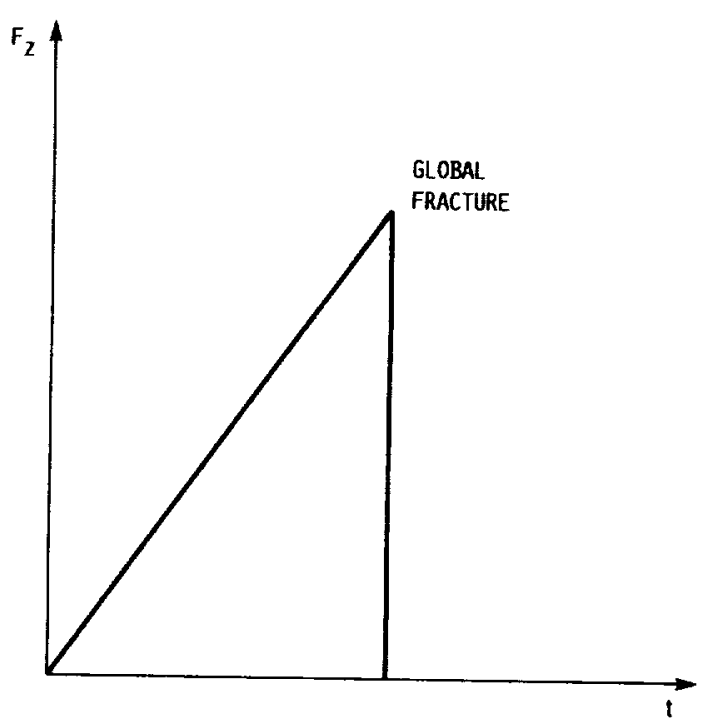

FIGURE 4. - VARIATION OF APPLIED LOADING WITH TIME.

LOAOING RATE - 0.1 LES/MICROSEC.

APPLIEO LOAD - 60 LBS. (B.E.)

STRESS (PSI)

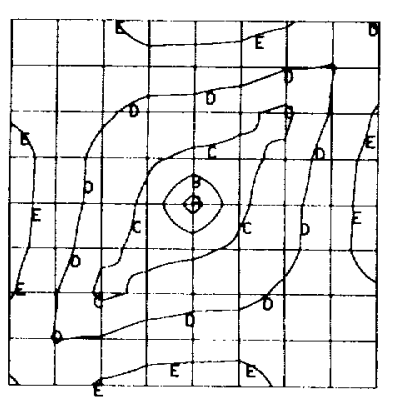

$1 B 984 .-A$

7428. - B

3872.- C

316. - D

$-3240 .-\varepsilon$

TRANSVERSE STRESSES FOR PLY 1

FIGURE 6. - STRESS CONTOURS AT INITIAL DAMAGE. 
LOAOING RATE - 0.1 LBS-MICROSEC.

APPLIED LOAD - 68 LBS. (A.E.)

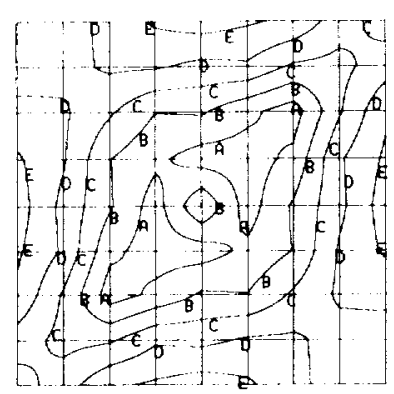

SUPPORT NOOES FREE IN $X-Y$ PLAME
STRESS (PSI)

3707. - A

$1768 .-8$

$-171 .-c$

$-5110 .=0$

$-4049 .=E$

TRANSVERSE STRESSES FOR PLY 1

FIGURE 7. - STRESS CONTOURS AT DYHAMIC EQUILIBRIUM AFTER INITIAL DAMAGE.

LOAO IMG RATE - 0.1 LBS-MICROSEC.

APPLIEO LOAO - 240 LBS. (A.E.)

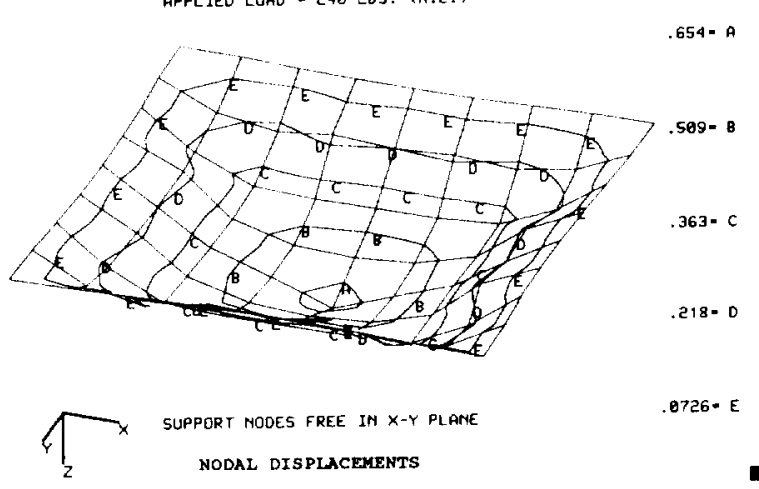

FIGURE 9. - DEFORMED PLATE AFTER DAMAGE GROWTH.
LOADIMG RATE - 0.1 LBS MMICROSEC

APPLIEO LOAO = 60 LBS. (A.E.)

DISPLACEMENTS (IN.)

$.274 *$ A

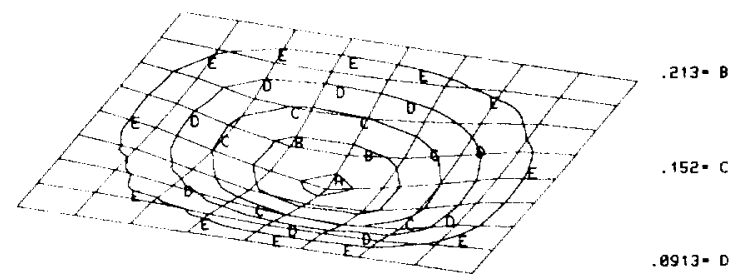

SUPPORT HOOES FREE IN X-Y PLANE

$.0384-E$

FIGURE 8. - DEFORHED PLATE AFTER INITIAL DAMAGE.

LOAOING RATE $=3.5$ L8S /MICROSEC.

APPLIED LOAD - \$OS LBS. IA.E.)

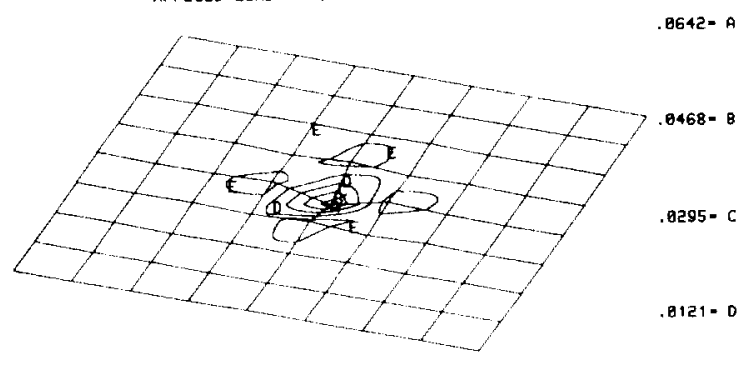

$\overbrace{x} \times$ SUPPORT MODES FREE IM X-Y PLAME

FIgURE 10. - DEFORMED PLATE AFTER IMITIAL DAMAGE. 


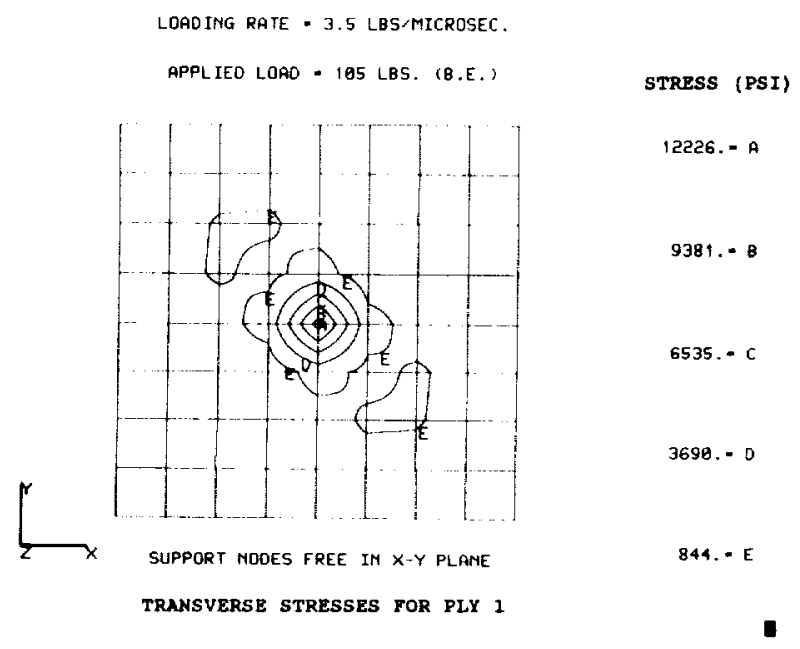

FIGURE 11. - IRANSVERSE STRESSES AT INITIAL DAMAGE.

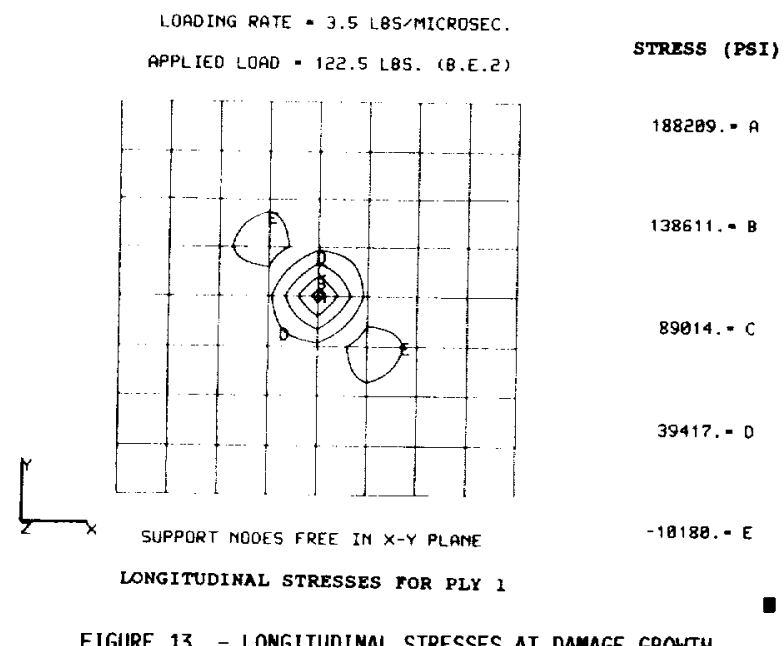

FIGURE 13. - LONGITUDIMAL STRESSES AT DAMAGE GROWTH.

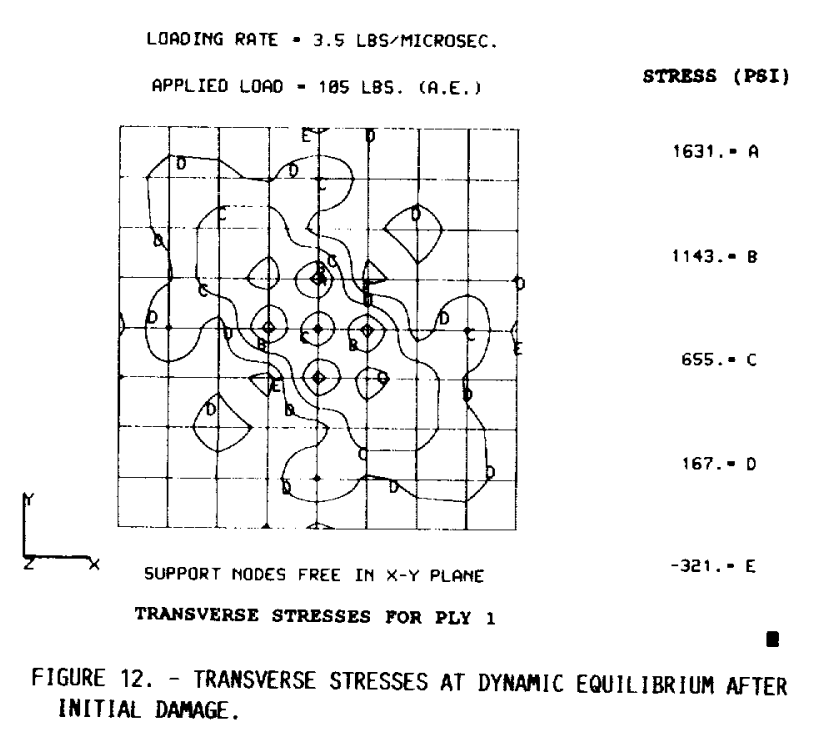

LOAOING RATE $=3.5$ LBS MICROSEC.

APPL IED LOAD - 122.5 LBS.

STRESS (PSI)

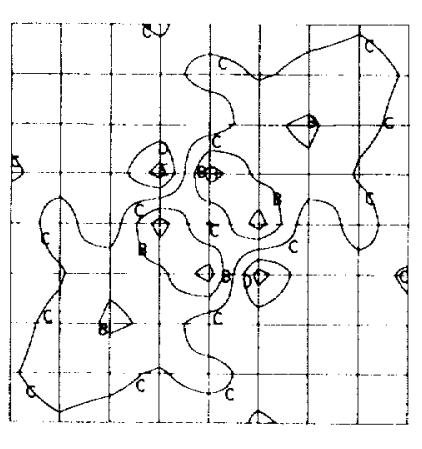

26145 . ค

13804.- 8

$1463 .=\mathrm{C}$

$-10878=0$

$-23219 .-\varepsilon$

FIGURE 14. - LONGITUDINAL STRESSES AT DYNAMIC EQUILIBRIUM AFTER DAMAGE GROWTH. 


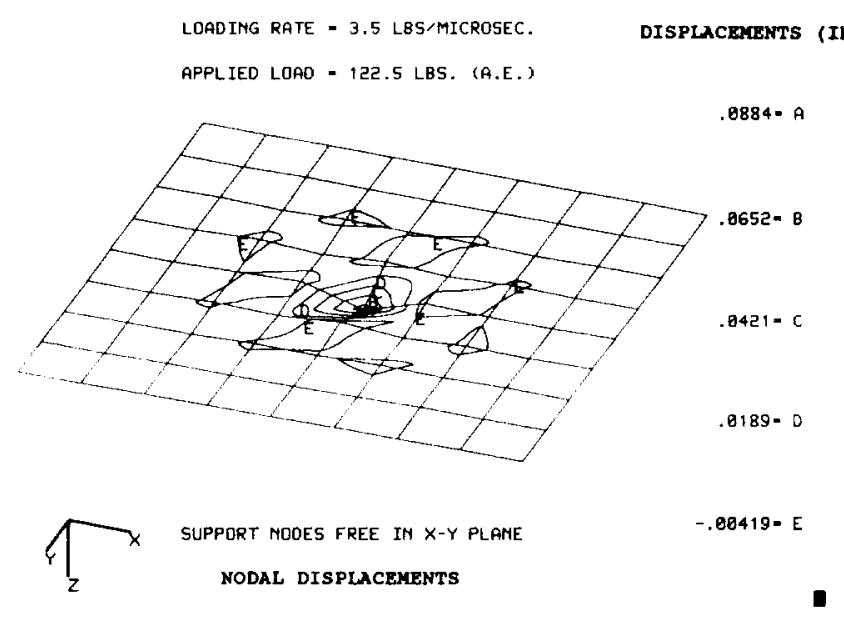

FIGURE 15. - DEFORHED PLATE AFTER DAMAGE GRONTH.

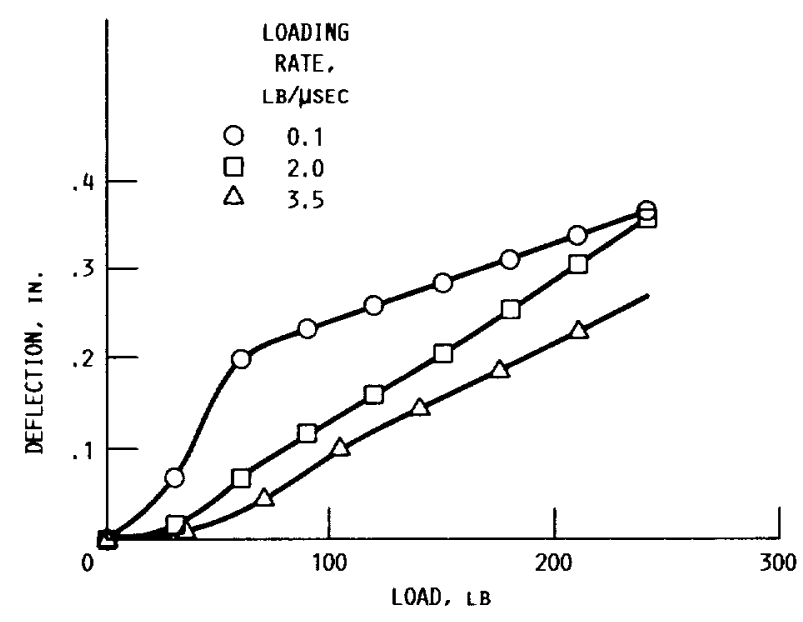

FIGURE 16. - LOAD-DISPLACEMENT RELATIONSHIPS FOR RESTRAINED SUPPORTS.

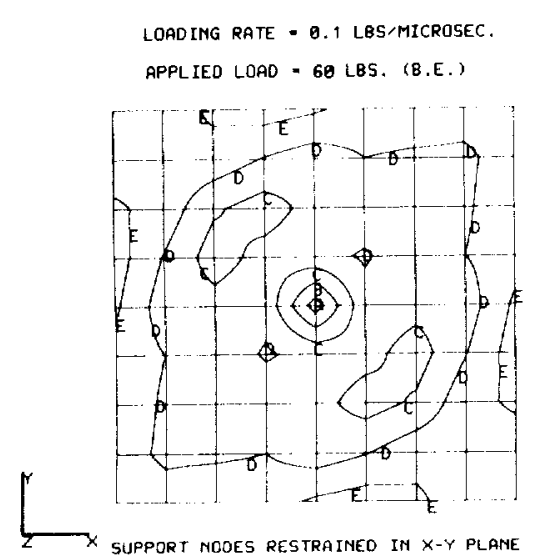

TRANSVERSE STRESSES FOR PLY 1
STress (PSI)

8283.- ค

$5848 .=8$

$34: 3 .=c$

979. - D

$-1456 .-E$

FiguRE 17. - tRANSVERSE STRESSES AT INITIAL DAMAGE.

LOAOING RATE $=9.1$ LBS/MICROSEC.

STRESS (PSI)

APPLIED LQAD - 6B LAS. (A.E.)

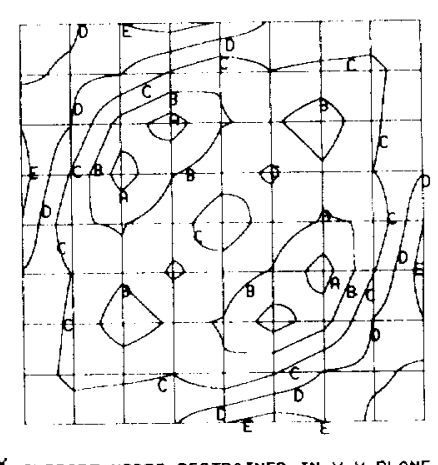

$3871 . .9$

$2417 .-8$

963.- C

$-492 .=0$

$-1946 .-E$ 


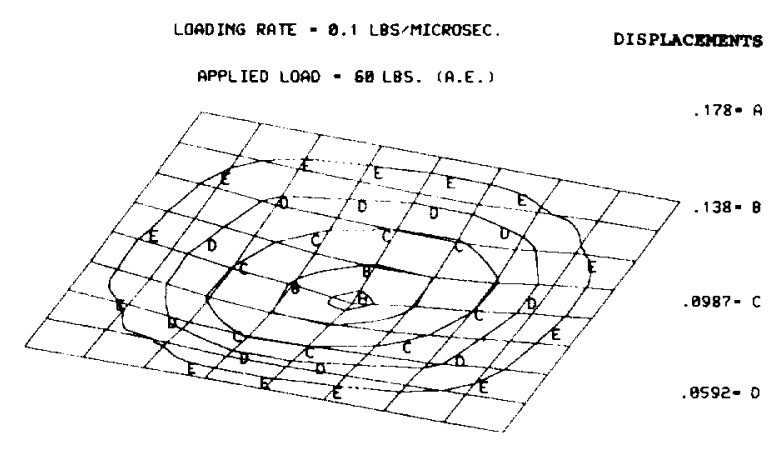

4 SUPPORT NODES RESTRAINED IN $X$ - $Y$ PLANE

NODAL DISPLACEMENTS

FIGURE 19. - DEFORMED PLATE AFTER INITIAL DAMAGE.
LOADING RATE - 0.1 LBS MIICROSEC.

APPLIEO LOAO = 248 LBS. (A.E,

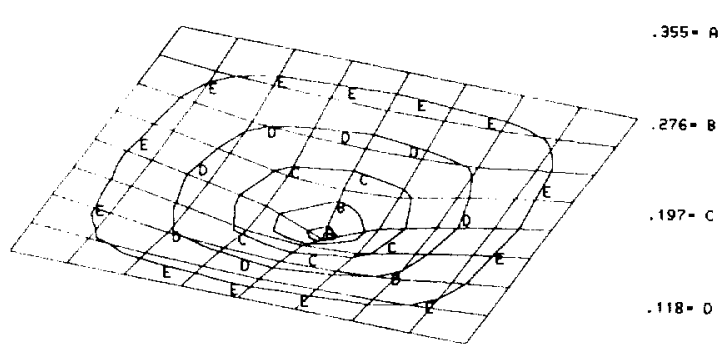

$4 X$ SUPPDRT MODES RESTRAINEO IN $X-Y$ PLAME

NODAL DISPLACEMENTS

. 394 - E
-

FIGURE 20. - DEFORMED PLAIE AFTER DAMAGE GRONTH.

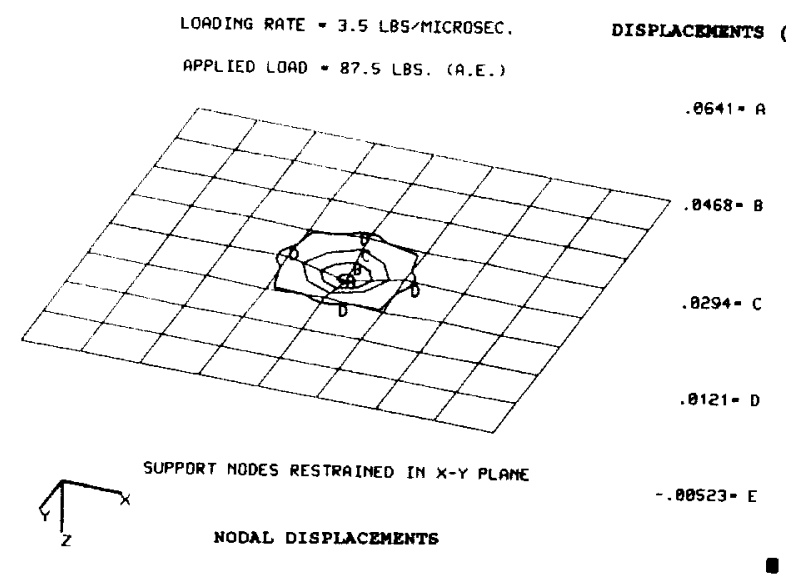

FIGURE 21. - DEFORMED PLATE AFTER INITIAL DAMAGE. 


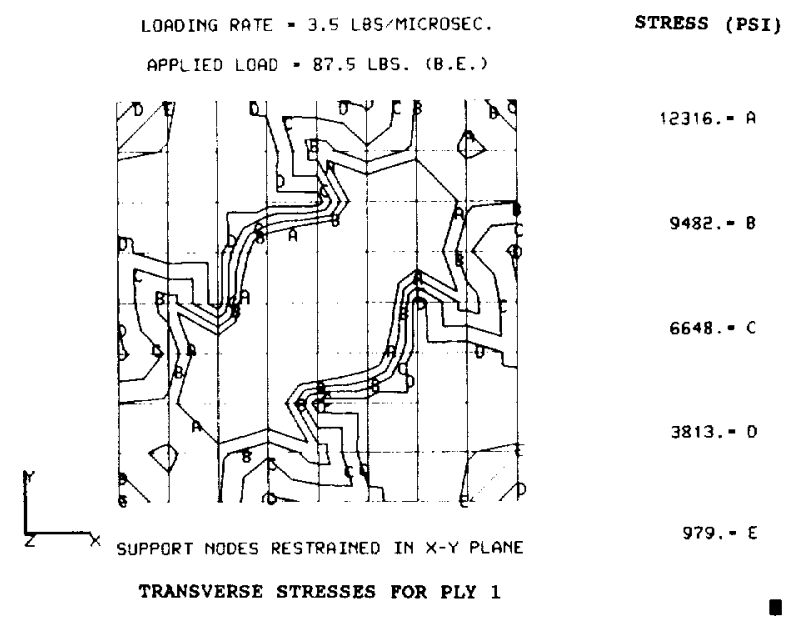

FiguRE 22. - tRANSVERSE StRESSES AT INITIAL DAMAGE.

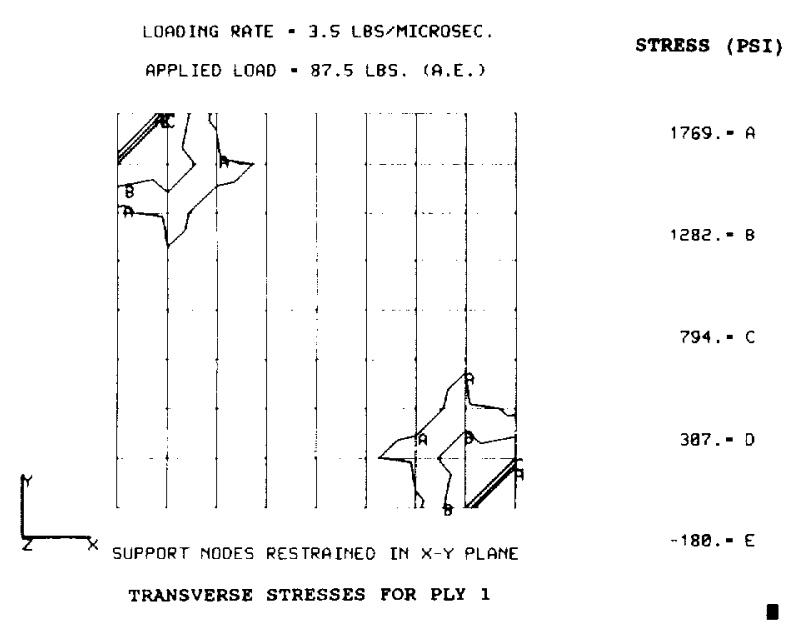

FIGURE 23. - TRANSVERSE STRESSES AT DYNAMIC EQUILIBRIUM AFTER INITJAL DAMAGE. 






National Aeronautics and

Space Administration

Lewis Research Center

Cleveland, Ohio 44135

Otficial Business

Penalty for Private Use $\mathbf{5 3 0 0}$
FOURTH CLASS MAIL

ADDRESS CORAECTION REQUESTED
|||||

U.S.MAIL

Postage and Fees Pars

National Aeronatillesing

Spare Adrinicitidion

NASTA 45 